\title{
Treatment of visual problems after intracorneal ring implantation
}

This article was published in the following Dove Press journal:

Clinical Ophthalmology

22 June 2013

Number of times this article has been viewed

\author{
Aydin Yildirim' \\ Hasim Uslu' \\ Necip Kara ${ }^{2}$ \\ Engin Bilge Ozgurhan ${ }^{2}$
}

'Fatih University, Department of Ophthalmology, Sema Research and Treatment Hospital, Istanbul, Turkey; ${ }^{2}$ Beyoglu Eye Research and Training Hospital, Istanbul, Turkey
Correspondence: Aydin Yildirim Fatih University, Sema Research and Treatment Hospital, Department of Ophthalmology, Sahil Yolu Sk No 16 34844 Dragos-Maltepe-Istanbul, Turkey Email draydinyildirim@hotmail.com
Purpose: To report the effect of wavefront-guided photorefractive keratectomy and corneal collagen cross-linking (CXL) on visual problems after Ferrara ring segment placement.

Materials and methods: A 32-year-old male patient was treated with a Ferrara ring segment for keratoconus. One year later, the ring was removed due to severe glare complaints. After 6 months, wavefront-guided photorefractive keratectomy and CXL were applied simultaneously to correct high order aberration and refractive error.

Results: Six months after the wavefront-guided photorefractive keratectomy and CXL, the uncorrected distance visual acuity was $20 / 25$, and there was a $30 \%$ decrease in coma aberrations. The glare complaint regressed.

Conclusion: Wavefront-guided surface ablation and CXL may reduce high order aberrations and glare complaints after intrastromal corneal ring implantation.

Keywords: keratoconus, Ferrara ring, corneal collagen cross-linking, corneal wavefront, photorefractive keratectomy

\section{Introduction}

Intrastromal corneal ring segments (ICRS), which were initially designed to correct mild to moderate myopia, have been demonstrated as a surgical option to manage keratoconus. ${ }^{1-3}$ Its therapeutic effects are based on the induction of remodeling of the corneal anterior and posterior surface's topography, which improves the optical quality of the cornea and reduces the optical aberrations, with consequent improvement in visual acuity. 4,5

Currently there are many types of commercially available ICRSs, such as Intacs ${ }^{\circledR}$ (Addition Technologies, Des Plaines, IL, USA), Keraring (Mediphacos, Belo Horizonte, Brazil), and Ferrara ring (Ferrara Ophthalmics, Belo Horizonte, Brazil). The Ferrara intrastromal ring segment used in this study has a small radius of curvature and a triangular anterior surface. ${ }^{6}$ The unique triangular shape with a flat posterior surface is purported to induce a prismatic effect on the cornea which reduces glare and halo. ${ }^{7}$ However these complaints were reported in $10 \%$ of the Ferrara cases followed over a 5-year period. ${ }^{8}$ Although these symptoms may disappear over time, pilocarpine or brimonidine tartrate drops are recommended for persistent cases. In addition, increase in high order aberrations (HOAs) after ICRS implantation is another problem that may affect visual quality.,10

The photorefractive keratectomy (PRK) plus corneal collagen cross-linking (CXL) procedure is an effective treatment option for progressive keratoconus. This procedure was found to be associated with stable refractive and topographic outcomes and with a 
reduction in corneal aberrations. ${ }^{11}$ Herein, we describe a case of visual complaint after Ferrara ring segment placement, which was treated successfully with wavefront-guided PRK and CXL procedures after the ring was extracted.

\section{Case report}

A 32-year-old male patient was referred to our department from an ophthalmology clinic, with bilateral keratoconus. He worked with heavy metals and could not use contact lenses or eyeglasses on the job. His uncorrected distance visual acuity was 20/200 and corrected distance visual acuity was $20 / 100$ with $-5.00-2.50 \times 30^{\circ}$ in the right eye. The uncorrected distance visual acuity was $20 / 70$ and corrected distance visual acuity was $20 / 40$ with $-2.50-2.00 \times 175^{\circ}$ in the left eye. The slitlamp examination and intraocular pressure and examination were normal for both eyes. Corneal topographi-
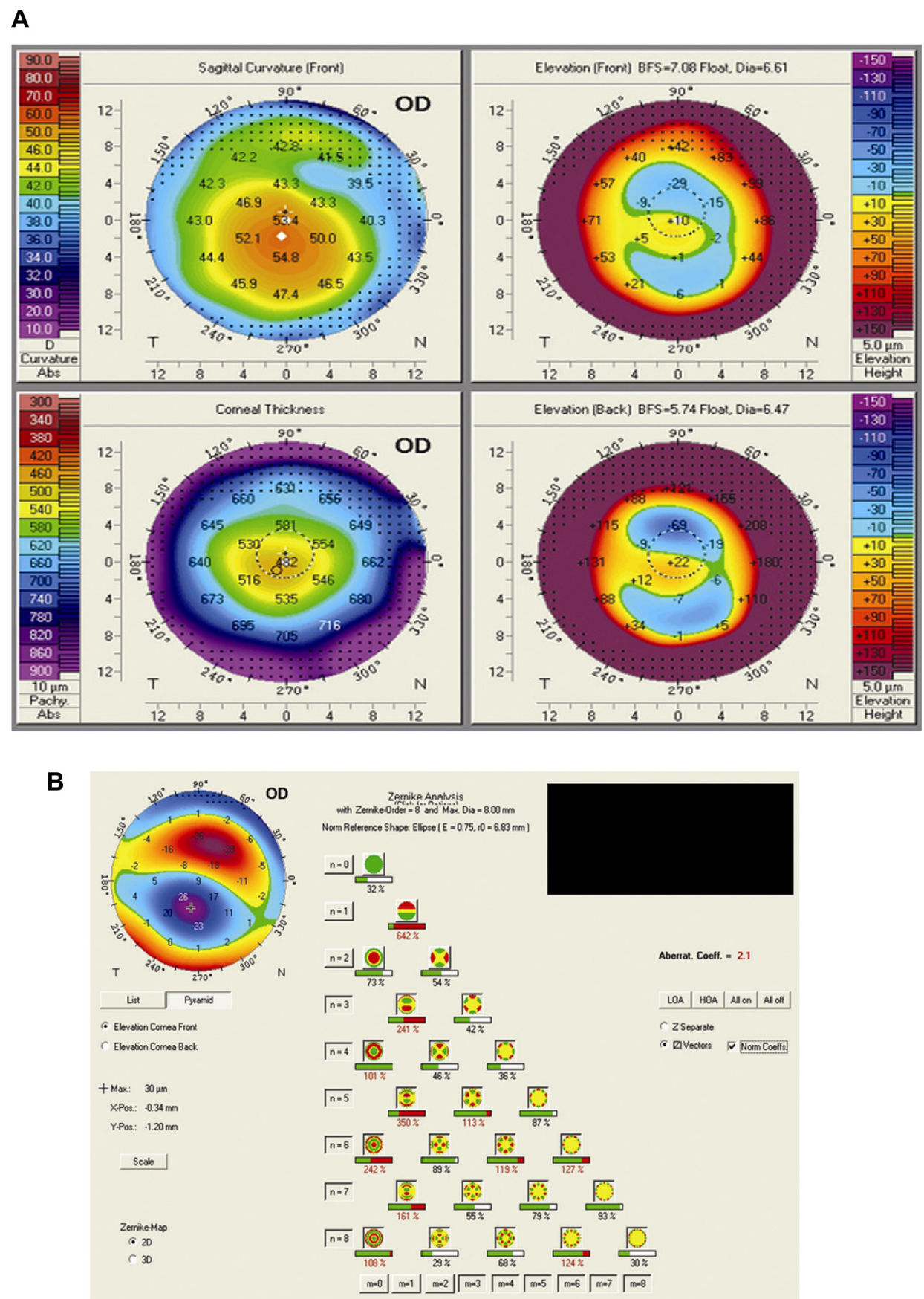

Figure I Corneal topography and wavefront aberration measurements prior to the ring placement.

Notes: Corneal topography shows central coned keratoconus pattern (A). Wavefront aberrations map shows primary and secondary vertical coma dominance (B). Abbreviation: OD, right eye. 
cal findings measured with Pentacam corneal topography system (Oculus Opticgerate GmbH, Wetzlar, Germany) revealed a keratoconus pattern in both eyes (Figure 1A). In the corneal wavefront map, measured with the WaveScan WaveFront ${ }^{\mathrm{TM}}$ System (Abbott Medical Optics, Santa Ana, CA, USA), primary and secondary vertical coma dominance was observed (Figure 1B). The aberrometry analyses under scotopic condition were based on a pupil diameter of $6 \mathrm{~mm}$.
The scotopic pupil diameter, measured with the Colvard pupilometer (Oasis Medical Inc, San Dimas, CA, USA), was $6 \mathrm{~mm}$.

In an attempt to improve vision, Ferrara ICRS implantation was planned for the correction of the corneal steepening and irregularity. Two Ferrara ring segments with $250 \mu \mathrm{m}$ thickness and $160^{\circ}$ arch-length were to be placed temporally and nasally using a $30 \mathrm{kHz}$ femtosecond laser (IntraLase ${ }^{\mathrm{TM}} \mathrm{FS}$
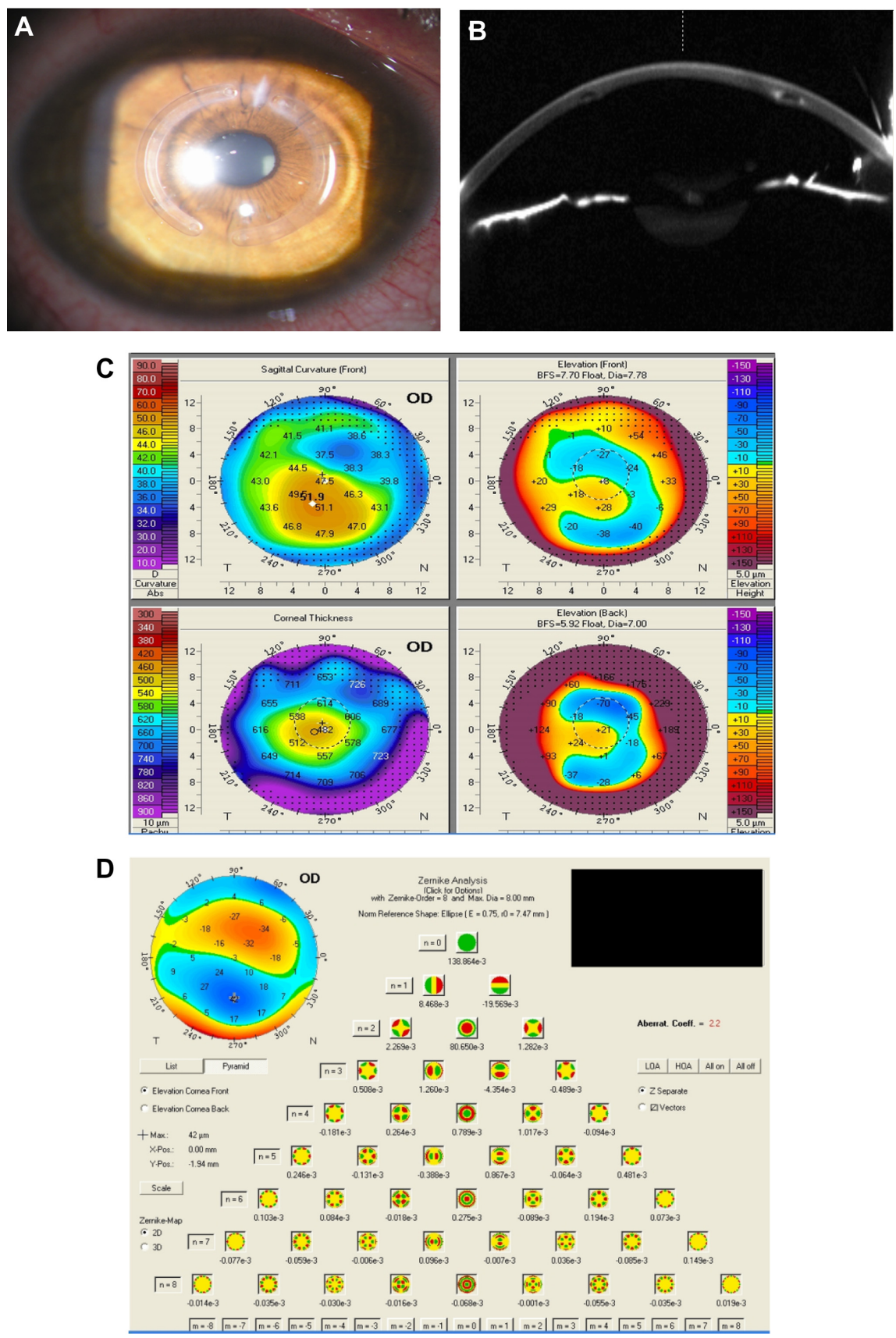

Figure $\mathbf{2}$ Imaging of cornea after ring implantation.

Notes: Slit-lamp photo and anterior segment optical cohorence tomography show optimal-centralized Ferrara ring segments (A and B). Corneal topography shows diminishing keratometric values (C). The Zernike Analysis with Pentacam shows increase in vertical coma and trefoil (D).

Abbreviation: OD, right eye. 
Laser, Abbott Medical Optics, ) in compliance with the Ferrara nomogram in the right eye. The Purkinje reflex was chosen as the central point. The patient rejected treatment of the left eye. After Ferrara ring segment implantation, the corrected distance visual acuity was 20/40 with optimal centralization of the ring segments (Figure 2A and B). However the patient had severe light glare complaints under photopic conditions in his right eye. Corneal topography revealed diminishing keratometric values (Figure 2C), and the Zernike analysis with Pentacam (Oculus Opticgerate $\mathrm{GmbH}$ ) showed an increase in vertical coma and trefoil (Figure 2D). Twelve months use of brimonidine drops did not eliminate this complaint. After 1 year, the rings were removed but the glare persisted. The aberrometric measurements taken from the right eye by WaveScan demonstrated that HOA root mean square error was $0.75 \mu \mathrm{m}$ and coma domination was $0.404 \mu \mathrm{m}$ (Figure 3A). Based on these results, wavefront-guided PRK along with CXL was planned to correct refractive errors and aberrations of the right eye.

The wavefront-guided ablation pattern was prepared using a WaveScan aberrometer and transferred to a VISX S4 IR device (Abbott Medical Optics, Santa Ana, California, USA).

A

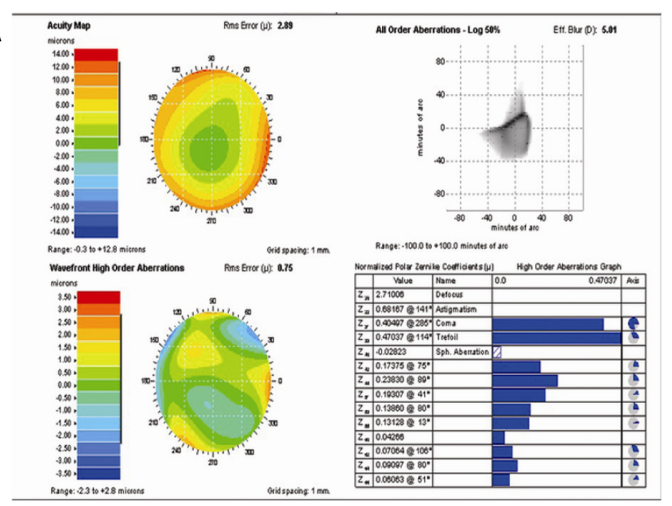

C

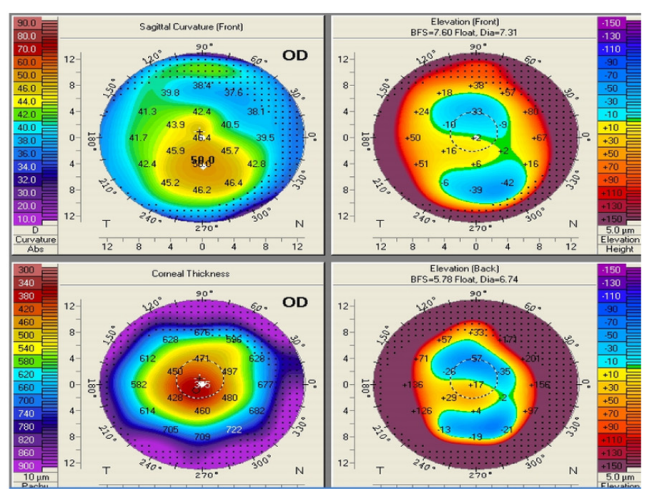

Estimated ablation depth was $50 \mu \mathrm{m}$. Mitomycin-c (Onko Ecza Sanayi ve Tic. Ltd., Sti., Istanbul, Turkey) at $0.02 \%$ was applied for 20 seconds to impede haze and regression. Following PRK, CXL was applied in compliance with the Dresden protocol. ${ }^{12}$ A $6.5 \mathrm{~mm}$ optical zone was used with a transition zone of $8.5 \mathrm{~mm}$. Six months after Wavefront-guided PRK and CXL procedures, the uncorrected distance visual acuity was $20 / 25$. The high order root mean square score was drawn back to $0.39 \mu \mathrm{m}$, and coma aberration was reduced to $0.277 \mu \mathrm{m}$ (Figure 3B). The patient's glare complaints ceased, and no haze was seen. At the 12 month visit, refractive status, visual acuity, wavefront analyses, and topograpgical measurements were unchanged (Figure $3 \mathrm{C}$ and D).

\section{Discussion}

Visual problems such as glare and halo are two of the expected complications after ICRS implantation, and it may adversely affect daily activities. Although no comprehensive studies have been conducted on glare and halo after ICRS implantation, one study showed that $10 \%$ of the Ferrara cases had halo complaint after surgery, and it has been associated with pupil size. ${ }^{8}$ In our case, glare complaint could not be

B

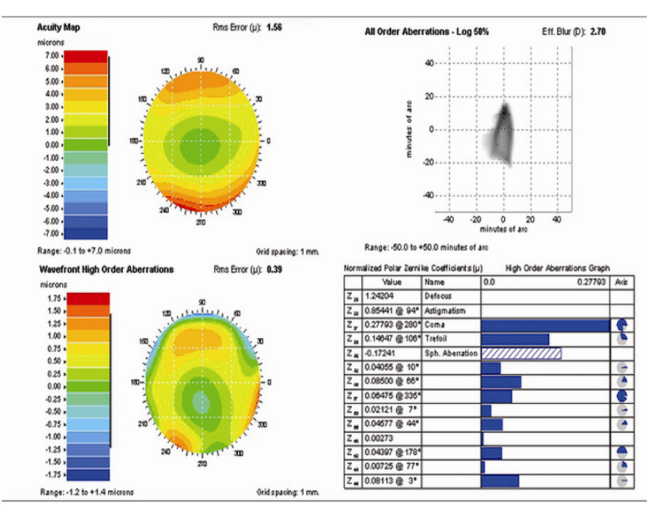

D

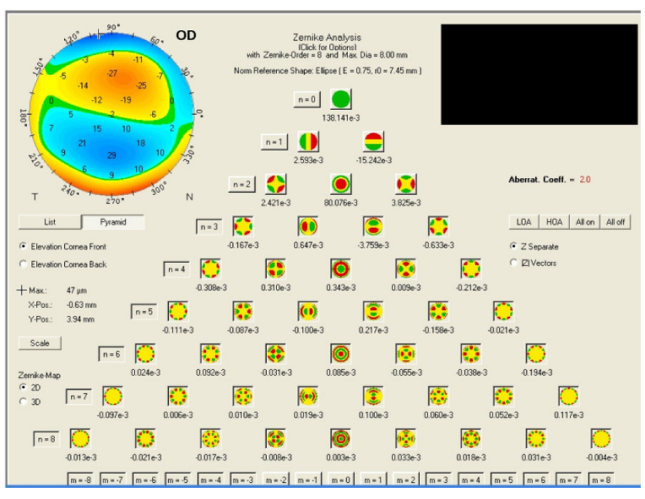

Figure 3 Wavefront analyses shows HOAs and total coma aberration continues I year after the ring segment removal (A). Six months after wavefront-guided PRK and CXL, wavefront analyses shows reduction in HOAs and coma aberrations (B). One year after wavefront-guided PRK and CXL, corneal topography (C) and wavefront analyses (D) show stability in keratometric and aberrometric values.

Abbreviations: CXI, corneal collagen cross-linking; HOAs, high order abberations; OD, right eye; PRK, photorefractive keratectomy. 
explained by pupil size, which was $6 \mathrm{~mm}$. We hypothesized that the cause of glare might be HOAs, and studies have shown increases in HOAs after ICRS implantation. ${ }^{9,10}$ HOAs can also have a significant impact on one's quality of vision and are often linked to visual glare and halos.

Glare symptom tends to get better over time. In severe cases, nighttime application of pilocarpine or brimonidine tartrate drops may be prescribed in order to constrict the pupil and alleviate undesired reflexes. Also Torquetti et al developed segments with a yellow filter in the matrix to avoid blue light at night, which can significantly decrease the incidence of glare and halos. ${ }^{8}$ In our study, after ICRS had been extracted, a combination treatment including wave-front guided PRK and CXL was applied to the patient. We achieved a reduction in HOAs and an improvement in glare symptom.

A few studies have reported the use of CXL along with topography-guided PRK in order to provide better visual rehabilitation in patients with keratoconus. ${ }^{13-17}$ Moreover, only one study, carried out by Kremer et al, has reported the use of wavefront-guided PRK along with CXL in keratoconic eyes. ${ }^{18}$ As we considered that our patient's glare symptom was associated with HOAs, we performed wavefront-guided PRK.

In summary, this report contributes new information to the literature. First, a severe glare complaint that is resistant to medical therapy may present after ICRS implantation. Second, symptoms of glare and HOAs may persist after the removal of ICRS. Lastly, wavefront guided PRK and CXL treatment may yield a reduction in HOA and an improvement of glare symptom in a keratoconic eye that has undergone ICRS extraction.

\section{Disclosure}

No financial support was provided for this study. This manuscript has been read and approved by all the authors. The authors report no conflicts of interest in this work.

\section{References}

1. Colin J, Cochener B, Savary G, Malet F, Holmes-Higgin D. INTACS inserts for treating keratoconus; one-year results. Ophthalmology. 2001;108(8):1409-1414.

Clinical Ophthalmology

\section{Publish your work in this journal}

Clinical Ophthalmology is an international, peer-reviewed journal covering all subspecialties within ophthalmology. Key topics include: Optometry; Visual science; Pharmacology and drug therapy in eye diseases; Basic Sciences; Primary and Secondary eye care; Patient Safety and Quality of Care Improvements. This journal is indexed on
2. Colin J, Cochener B, Savary G, Malet F. Correcting keratoconus with intracorneal rings. J Cataract Refract Surg. 2000;26(8):1117-1122.

3. Siganos CS, Kymionis GD, Kartakis N, Theodorakis MA, Astyrakakis N, Pallikaris IG. Management of keratoconus with Intacs. Am JOphthalmol. 2003;135(1):64-70.

4. Shabayek MH, Alió JL. Intrastromal corneal ring segment implantation by femtosecond laser for keratoconus correction. Ophthalmology. 2007;114(9):1643-1652.

5. Alió JL, Shabayek MH, Artola A. Intracorneal ring segments for keratoconus correction: long-term follow-up. J Cataract Refract Surg. 2006;32(6):978-985.

6. Kwitko S, Severo NS. Ferrara intracorneal ring segments for keratoconus. J Cataract Refract Surg. 2004;30(4):812-820.

7. Siganos D, Ferrara P, Chatzinikolas K, Bessis N, Papastergiou G. Ferrara intrastromal corneal rings for the correction of keratoconus. J Cataract Refract Surg. 2002;28(11):1947-1951.

8. Torquetti L, Berbel RF, Ferrara P. Long-term follow-up of intrastromal corneal ring segments in keratoconus. J Cataract Refract Surg. 2009;35(10): 1768-1773.

9. Piñero DP, Alió JL, El Kady B, et al. Refractive and aberrometric outcomes of intracorneal ring segments for keratoconus: mechanical versus femtosecond-assisted procedures. Ophthalmology. 2009;116(9): $1675-1687$.

10. Chalita MR, Krueger RR. Wavefront aberrations associated with the Ferrara intrastromal corneal ring in a keratoconic eye. J Refract Surg. 2004;20(6):823-830.

11. Alessio G, L'abbate M, Sborgia C, La Tegola MG. Photorefractive keratectomy followed by cross-linking versus cross-linking alone for management of progressive keratoconus: two-year follow-up. Am J Ophthalmol. 2013;155(1):54-65.

12. Spoerl E, Mrochen M, Sliney D, Trokel S, Seiler T. Safety of UVAriboflavin cross-linking of the cornea. Cornea. 2007;26(4):385-389.

13. Krumeich JH, Kezirian GM. Circular keratotomy to reduce astigmatism and improve vision in stage I and II keratoconus. J Refract Surg. 2009;25(4):357-365.

14. Kanellopoulos AJ, Binder PS. Collagen cross-linking (CCL) with sequential topography-guided PRK: a temporizing alternative for keratoconus to penetrating keratoplasty. Cornea. 2007;26(7): 891-895.

15. Kymionis GD, Kontadakis GA, Kounis GA, et al. Simultaneous topography-guided PRK followed by corneal collagen cross-linking for keratoconus. J Refract Surg. 2009;25(9):S807-S811.

16. Kanellopoulos AJ. Comparison of sequential vs same-day simultaneous collagen cross-linking and topography-guided PRK for treatment of keratoconus. J Refract Surg. 2009;25(9):S812-S818.

17. Al-Tuwairqi W, Sinjab MM. Intracorneal ring segments implantation followed by same-day topography-guided PRK and corneal collagen CXL in low to moderate keratoconus. J Refract Surg. 2013;29(1): 59-63.

18. Kremer I, Aizenman I, Lichter H, Shayer S, Levinger S. Simultaneous wavefront-guided photorefractive keratectomy and corneal collagen crosslinking after intrastromal corneal ring segment implantation for keratoconus. J Cataract Refract Surg. 2012;38(10):1802-1807. 